\title{
EPILEPSY WITH RETROGRADE AMNESIA.
}

\section{A Medico-legal Study of the Case of Amos D. Palmer.}

\section{BY EDWARD COWLES, M. D.,}

\author{
McLean Hospital, Waverley, Mass.
}

The case of Amos D. Palmer, of Providence, who killed his wife on the night of February 12, 1899, presents some points of peculiar medico-legal interest. At his trial in June he was acquitted of the crime of murder on the ground of "insanity," though never before the act having been considered insane, except that he was generally regarded as somewhat mentally deficient. The management of the expert testimony by the court and counsel on both sides was unusual and creditable to them; and the elucidation by the defense of the nature and cause of Palmer's irresponsibility for the crime gave the case a unique character.

This study of the case being made from a medical point of view, its data will be presented here by following in a general way the order in which they came to the knowledge of the experts for the defense. The prisoner was in jail at Howard, R. I., and the first two examinations were made by Dr. Geo. F. Jelly, February 25 and March II ; the writer was present on the second visit. Dr. Walter Channing joined us later, and his study of the "Stigmata of Degeneration" in this case is published in connection with this paper, which the writer has the privilege of presenting as our joint report. The history of Palmer's life, as known by others and told in part by himself, was then learned by us; this, with the main incidents of the homicide, may be summed up as follows:

Amos D. Palmer was born in Providence in 1860 ; his parentage was most respectable. There was insanity in collateral branches of his mother's family; her mother's sister was insane, her father's brother was eccentric, and his niece insane. The father of young Palmer dying a few years after the son was born, he grew up solely in the care of his 
mother; she was a well educated woman, proud of her ancestry, reputed wealthy and lived well, but regarded as eccentric. A notable indication of this was thought to be the manner in which she brought up her son. She never sent him to school, but herself gave him what education he had. During his childhood and youth she kept him closely at home attended by a nurse; he was a weak and sickly child. She went with him when away from home, led him to church, etc., and had him sleep with her till he was 14 or 15 years old, and sometimes when he was older. He never had much to do with other boys, grew up with no occupation, and was considered by those who knew him as physically weak and mentally defective. After he was 20 years old he had more liberty; he fell into bad company and became notorious for his drinking habits and sexual excesses. At the age of $3 \mathrm{I}$, after an intimacy of 2 years, under these circumstances, with a young, divorced woman, he married her without the knowledge of his mother, with whom he continued to live and who died 4 years later, leaving him $\$ 250,000$. He then took his wife to his home and acknowledged her. He was fond of her; it was said that he was seen apart from her only on a few occasions during the remaining 4 years of their married life. His drinking habits abated; she made him stop drinking at bars. He says she had a high temper and was jealous of him; they sometimes quarrelled and she almost completely dominated him. He drank beer regularly at home and had whiskey in his cellar; but while she indulged him and herself in this regard, she habitually chided him, sometimes with reason and sometimes without, if she thought he drank too much or was liable to do so. He was naturally an amiable, peaceful man. During the last 3 years the unpleasant occasions were rarer and they lived more happily than ever before. Within a few months before her death he had given her property to the value of $\$ 40,000$. His young relatives had begun to visit them and, at the time of the tragedy, they were living in Cranston in a large house with few near neighbors. There had been some burglaries in the vicinity and, speaking of their fears in this regard, Mrs. Palmer told one of their friends that she had a revolver. On the i2th of February they celebrated the eighth anniversary of their marriage; four young people were invited to dine with them-a married couple, the wife being Palmer's cousin, and another couple soon to be married, the young woman being also his cousin. They came late-after 2 o'clock-being delayed by the stormy weather; Mr. and Mrs. Palmer had already dined. The two men drank cocktails, but Palmer did not; it being a cold day and having to attend to the furnace he drank whiskey three or four times in the cellar that afternoon, using a small glass and taking about one ounce each time. The three men went u.p stairs to the billiard-room about 5 o'clock; the women went to Mrs. Palmer's room. The men had each a bottle of beer before going up, and by 8 o'clock each had consumed in all about three bottles of it. The others testified that there was nothing to indicate that Palmer was intoxicated, or to distinguish his conduct from what it usually 
was. He played billiards as usual; but after the women joined them at 8 o'clock his wife commented upon his poor playing and he made a difficult shot to show that he could do it. The company went away at 8.30, Palmer helping his guests to put on their coats, talking with them of the coming marriage, while waiting in the parlor for the street car until they left. The testimony is positive and convincing that he showed no signs of being under the influence of liquor, but was sober and natural in manner, and on pleasant terms with his wife. They then had luncheon in the kitchen, the cook being present; she testified that Palmer spoke of hearing an unusual noise in the pipes and of going to fix the furnace, and that Mrs. Palmer told him he should leave such things to John (the coachman), and that he wanted to go down there to get a drink; Palmer replied that he fixed the fire as he wanted it and it was all right. It has been stated that later that night the cook said that he was under the influence of liquor at the time of the luncheon; she testified at the trial that he "was not drunk at all, but appeared to have had a glass or two." She also stated, at a previous examination, that after Mrs. Palmer remarked that John should see to the furnace, she took a notion she would go down herself, which she did, and that Palmer went down after her. At an early examination, the coachman also related that as he was going to fix the furnace, shortly before the alarm of the shooting, he was told by the cook that Mr. and Mrs. Palmer had just been down there together. With respect to the apparent conflict of the cook's first statement with her later one as to Palmer's intoxication, it became evident she had a theory that this was the cause of his killing his wife. That the latter should have accused him of the intention of drinking was characteristic enough of her not to warrant the inference that she meant that he was then intoxicated; it appeared conclusive to Dr. Jelly, Dr. Channing, and the writer, in the final study of the case, that the weight of evidence was that Palmer drank only three to four ounces of whiskey and no more than three bottles of beer during the hours between 3 and 9 o'clock and nothing before that time, during the day. The possibility of his having drank a considerable quantity on his last visit to the cellar before the latter hour is excluded by the presence there of his wife. It is pertinent to state here that it was his custom, every night, to take a bottle of porter from the cellar to his room to open it there, and for his wife to come there and drink it while sitting and talking with him just before retiring to her own room. An empty porter bottle was found on the floor near her dead body. It will be seen hereafter that these particulars are of great importance in determining the naturalness of the circumstances up to a certain time in the events of that evening.

At the time of the second examination of Palmer, March I I, by Dr. Jelly and the writer, the foregoing data were substantially presented, except the corroborative details that were learned 
afterwards. The main facts of the chief event were stated: Shortly before 9 o'clock Palmer and his wife went to their rooms; at about 9.20 sounds of pistol-shots were heard; shortly afterwards Palmer called the servants and was found acting strangely and his wife lying dead upon the floor of his room; physicians and officers were called and thought he was intoxicated; and he was taken to prison in the morning. In addition, we had the assertion of Palmer that he remembered all that occurred the day before, including his carrying the bottles of beer up to the billiard-room about 5 o'clock, but that his memory stopped there; that he had a brief and dream-like vision of his wife lying on the floor, and his first recollection thereafter was of Dr. Hersey standing before him and handing some medicine to him. The physical examination made on the second visit gave negative results, except that his right pupil was somewhat larger than the left; there was at first a slurring of speech, and a general aspect that suggested paresis. He gave an account of having had no illnesses except delirium tremens some years before; and of two attacks of sunstroke: one was in the summer of 1897 , when he fell from his wheel while riding with his wife, and lay by the roadside for half an hour, but he does not think that he was entirely unconscious; and the other attack was in the summer of I 898 , when driving he was taken suddenly ill and obliged to give the reins to his wife and was taken home.

Upon the facts presented at this stage of the medical inquiry, the conclusion was reached that Palmer was congenitally defective, never had developed normal intelligence, and that his condition had been aggravated by excessive drinking and sexual indulgence. The question of paresis was disposed of as will be seen in Dr. Channing's study of the degenerative aspects of the case. Its problem included several questions for solution:

I. Was there a loss of memory by Palmer of the events described from about 5 to II o'clock on the night of his killing his wife, except the brief interval when he remembers seeing her lying on the floor? In other words, did he tell the truth, and if so, how is the amnesia to be accounted for?

2. Was he intoxicated and in a state of alcoholic amnesia?

3. Were the two attacks of "sunstroke," in $1897-98$, related to the amnesia of February 12, 1899, as suggesting the question of epilepsy? 
4. What relation to these had the occasional habitual appearances of absence of memory and "vacant stare" during conversation, described by his relatives?

The first of these questions was convincingly answered through the tests applied in a number of lengthy examinations subsequently made, in which Dr. Channing became one of the examiners. Our conviction was that Palmer was absolutely truthful. With his evident good breeding and amiable disposition, he showed a conscientiousness native to his character. Lacking in imagination, there was little power of combination; his memories were curiously stereotyped statements of concrete facts; what he remembered he knew, and when he did not recollect a thing he said so. He always told his story substantially alike, except with the natural loss of some minor details as time went on. After getting his consecutive history of his whole life, with care to ask as few leading questions as possible, the inquiries directed to any point in it, at the different examinations, always brought consistent answers; upon our referring to his previous statements of what he and others had said on many different occasions, he had a habit of saying " or words like that." After we became well assured of his truthfulness, we did not succeed in inducing him by leading questions to enlarge or change his account of his numerous experiences pertinent to the case. There was a certain artless lack of appreciation of the purpose of the inquiries. His statements in regard to what was testified to by others were always consistent with his truthfulness. This was so convincing that his counsel took the extraordinary course of placing him first upon the witness-stand in his own defense, when his story produced the same effect upon those who heard it; the same conclusion was confirmed in the minds of all the medical experts, on both sides, in the joint examination of him that was permitted when the trial was stopped after only a part of the evidence in his behalf had been presented.

Returning to the questions already stated as forming the problem of the case in the early stage of the medical inquiry, they were soon reduced to a single issue: Was the amnesia at the time of the homicide due to alcoholic intoxication or to epilepsy? Before our third examination, Palmer was questioned in regard to his early life as to why his mother did not have him 
go to school, and if he remembered any illness, or anything like fits. His answer was: "No, but my mother told me that I had convulsions." He described what he remembered of those attacks when he was between 12 and I 5 years old, and recollected that his mother told him he had been " subject to convulsions" before that age. A difficulty in following this and other inquiries at once appeared: his mother, the nurse in his childhood and youth, and the family physician were dead, and also the physician who attended him in the two attacks of "sunstroke" in 1897-98.

From this point in this study of the case it will be made to proceed more intelligibly by recounting first the testimony of others in regard to the incidents immediately connected with the homicide, in the few hours after 9 o'clock, at which time, as already stated, Palmer and his wife went to their rooms. These particulars are of the greatest importance in determining the diagnosis of his condition. The evidence indicates, it will be remembered, that then there was no appearance of his being " under the influence of liquor," and equally of there being no difference in his appearance and manner suggestive of an alteration of consciousness which might explain the amnesia. Following these particulars, a review of the history of epilepsy during his lifetime, and his own returning memories after the homicide, will complete the data for discussion.

At about 9.20, the cook, sitting in her room, with doors closed between front and back hall on the $2 \mathrm{~d}$ floor, heard a sharp pounding noise 4 or 5 times; she heard Mrs. Palmer scream and Mr. Palmer's voice, but could not hear what was said. In a few minutes Palmer opened the door leading from front to rear hall, looking excited and frightened, and said, "Mary, did you hear that?" She asked what was the matter and he answered, "I don't know, I'm afraid I've killed her." She went into his room, saw the pistol lying there, and found Mrs. Palmer lying on the floor with her head on a hassock. The cook said, "Mr. Palmer, what have you done "; he said, "'Twas her that tried to kill me first." "Oh, what have I done, what have I done!" They were both in night dresses with bath robes over them; Mrs. Palmer had on shoes and stockings. She lay as if she had fallen backward, with clothing not disarranged, her head upon a hassock. There were found afterwards no signs of a struggle or of disorder in the rooms. Her clothing and jewelry worn that day were in their proper places. ${ }^{2}$ The cook went to call John, the

${ }^{1}$ The position may be understood by noting that, with the head of the bed standing against one side of the room, Mrs. Palmer used to sit by a 
coachman, who testified that he went up and found Mr. Palmer standing in the hall about a foot from the door of his room without any clothes on, back to the door, and his arms up in the air. Another servant testified that she heard him screaming at that time. After a minute, the coachman says, "I asked, 'What is the matter? what is the matter?' and he turned on me in a wild rage and said, "Who are you? who are you? who are you?' I said, 'I am John, don't you know me?' It was 3 or 4 minutes before I could make him understand who I was. He knew me by spells and then he would go off. He said, "What have I done? what is the matter?" "The coachman got Palmer into his room where his night clothes were found lying on the floor and helped him to dress. The revolver was lying on the bed; Palmer picked it up and said, "I will shoot myself." John said, "Don't do it, have some sense," and Palmer dropped it on the bed. John put it in his coat pocket and later carried it away. After that Palmer went to the bureau and took out another pistol, and said, "I will kill myself." -John again said, "Don't do it," and this pistol was dropped on the bed; it was afterwards found to be out of order. About this time Palmer said, "Have I killed my wife?" "What have I done?" "Have I killed my wife?" These expressions were repeatedly made; he was taken across the hall to the sitting-room. John was alarmed at Palmer's appearance when he found him in the hall-he appeared wild and bewildered, dazed and tremulous, and in some other condition than he had ever seen him in before, in his 12 years in the family. Palmer did whatever the coachman directed.

John then insisted on Palmer's telephoning for a doctor, telling him the number to call; Palmer called, "This is Amos D. Palmer, I believe I have killed my wife. I leave it all with you." This was after Io o'clock, and Dr. Hersey came about II o'clock. Dr. Perkins came at about II.30.

Dr. Hersey found Palmer standing with the coachman on the stair landing; Palmer seemed surprised to see the doctor, appeared in a dazed condition, and did not seem to realize what was going on; he was not violent at that time. Dr. Hersey found Mrs. P. lying on the floor, as has been described; told Palmer she was dead; he was very much excited and continued so for two hours after that, and had to be followed from room

table and drink the porter at the opposite side of the room where Palmer could see her as he lay on the bed looking over the foot of it while talking with her, as was the custom. Near the head of the bed was the high bureau, in the top driwer of which the pistols were sometimes keph. Her body lay obliquely alongside the bed, with the head nearer to the bureau than the feet; near them lay an empty porter bottle in the direction toward the place where she is supposed to have been sitting. Palmer says that about six weeks previously the pistols were in the place described, and he has no recollection of having seen them afterwards. The medical examiner reported that five bullets entered the body; one entered the left arm; one went through the heart, and others passed near it. 
to room; he wanted to go out of doors, and said repeatedly, "Doctor, why did I do it?" and that he wanted to kill himself; seemed to be suffering from nervous shock; kept moving about the room; was given doses of bromide of sodium; he became gradually calmer, and about I to 2 o'clock was rather quiet, but before that time the doctor couldn't get much out of him. After that Palmer said he had 4 drinks of whiskey, and some beer afterwards, that must have knocked him out; that he didn't recollect his friends going away, but remembered being in the billiard-room drinking beer, and he appeared as one affected by alcoholism and nervous shock; he smelt of liquor. From 1 to 2 o'clock he answered questions very well, but the doctor couldn't get out of him what happened during the evening. Palmer said it was all a blank after going up to the billiardroom, and asked the doctor to explain it. Following the announcement of his wife's death Palmer changed from his dazed, spiritless condition to one of excitement. Dr. Perkins, medical examiner, arrived before 12 and found Dr. Hersey sitting beside Palmer and holding his hand. He testified that Palmer would get up and walk across the room, repeating, "Why did I do it? why did I do it? I couldn't have done it." It was impossible to get any explanation from him of what led up to the act. Dr. Perkins thought Palmer was suffering from acute effects of alcohol and remorse for what he had done; thought he knew he had done it, when saying, " How could I do it? I couldn't have done it." Dr. Perkins said his memory appeared to have stopped in the billiard-room and to have begun to return after Dr. Hersey came; sometimes he remembered, and then did not remember; he could talk rationally most of the time and there was no stupor; the evidence of alcoholism was " his own statement, smell of breath, and general appearance consistent with it."

The chief of police, who came about 1.30, testified that he thought Palmer appeared rational and that he did not see any evidence of liquor, but that Palmer said he had drank some. Another officer knew that Palmer had been drinking, because he could smell his breath, but he was rational. He was given some coffee between 3 and 4 o'clock and then was sick and vomited. He repeatedly said, "Did I do it? how did I come to do it?" He would come up to the officer spoken to, and put his hands on his shoulders, repeating these words. In the early morning he was taken away to Court and sent to jail. The theory of the Government was, that the crime was committed by Palmer while under the influence of alcohol. Palmer himself had no other theory to offer, but this did not satisfy him; the amount he drank was not sufficient and he conjectured that it was taking beer on "top of the whiskey" that made the trouble, or the extra strength of the "Mt. Vernon" brand. This latter point was brought out at the trial, but, though in favor of the prosecution, if true, appeared to have no importance.

The manifestations of epilepsy were explicitly testified to by witnesses who knew Palmer from his early childhood when they were boys. Three credible men, who were his neighbors and playmates for a number of 
years, remember him as sickly and puny, subject to strange attacks, having a nurse to take care of him and rarely being allowed to leave his own premises. This was when he was 6 years old and upwards. They remembered that on many occasions, when playing together, young Palmer would suddenly laugh, cry out, jump up and clap his hands; sometimes he would run into the house and the nurse would come and say he could not come out again, or they would call the nurse. Four or five occasions were remembered when, beginning with the actions described, he fell to the ground, was rigid, and the nurse came and carried him in. Other witnesses, including the milkman, knew him during all his childhood; the latter when taking Palmer to ride on his wagon saw like attacks when he would "become pale, turn purple, and quiver," and would have to be taken home and carried into the house. These attacks occurred up to the age of 14 to 16 years. It was understood that he did not go to school because of his mother's fear that he might have convulsions. The family physician was in frequent attendance. Palmer himself recollects three severe attacks when he was 12 to 15 years old. His memory of the last one enables him to describe it: "In the evening when lying on the couch suddenly an all-gone feeling came over me such as I had before when I was to be very sick." "I lost myself entirely all night." "I had trouble to catch my breath and became unconscious." "I was frightened and thought I was dying, cried out just as I was going off." "My mouth felt swelled up and sore afterwards." " Mother told me I had convulsions and was very sick, and the dector had been with me all night." She told him he must be careful about what he ate because he had convulsions. The doctor said he must not eat much meat. He remembers no more "convulsions" after he was 15 ycars old; for some years after that he would cry out in the night, and wake up frightened in bed, and his mother would come to him; two or three times he was found by her at the window and waked up. He remembers that sometimes on waking in the morning his mouth was sore. At the age of $2 \mathrm{I}$ years he felt faint and fell on the sofa in his room. During the subsequent years of his life he had "faint turns," how often he cannot tell, but not frequently, when, he says, "I would feel all-gone as if I would collapse, and as if I would be going to have a convulsion. The feelings would remind me of those when I had one." When alarmed by these occurrences he would sometimes be careful about his diet and refrain from eating meat for a time. He never liked to speak of these experiences.

After the apparent cessation of the major attacks, when he was 15 years old, the manifestations of epilepsy appear to have continued chiefly in the form of sensory or psychical equivalents, of which he has little. memory, except on some recent occasions. An important witness was the barber who attended Palmer frequently at his home in Providence. for a number of years after 1885 . Once in that year, when Palmer was 25 years old, he complained of feeling ill and suddenly cried out," Oh! Oh!" stiffened in his chair, threw his head back, his face looked purple. 
and he struggled. His mother said he was ill. This was the only attack of that kind the barber ever saw, but he testified at the trial to other "peculiarities" in such a way as to seem to think that Palmer had very frequent "attacks." As this testimony has been criticised it is well to note here that a subsequent explanation made by the barber to the writer shows that the "vacant stare" and "dropping jaw" mentioned as "peculiarities" were merely what has been observed by others as habitual to Palmer; also the peculiar movement of hair-clippings rubbed in the hands were what everyone can see, but that Palmer frequently laughed at it seemed peculiar and foolish; but it was of possible significance that on a few occasions in 12 years Palmer would point to some article and "break out and say, 'Isn't that furniture moving?" " On a few occasions he said, "I think there is something the matter with me, I guess I see double."

It has been stated that Palmer had two attacks which he called sunstroke. The first was in 1897; he says his head felt bad, he had no control over himself and fell from his wheel; his wife was with him and he lay by the roadside half an hour, but not entirely unconscious, and had not been drinking. He got home with difficulty. The doctor, who has since died, instructed him to be moderate in his way of living; and that he must eat very little meat, he must not get excited, and if he was not careful he would have a worse attack. The second attack remembered by Palmer, in 1898 , was testified to by a witness who saw him in the carriage reclining on the back seat partly supported by another person; he looked pale and almost lifeless. Mrs. Palmer and his friends were alarmed and excited; some ice was put upon his head. $\mathrm{He}$ was taken home and the doctor was called; Mrs. Palmer said, "He has had one of those bad spells." Palmer remembers that on several occasions since 1897 he has found blood in his mouth on waking in the morning, and his tongue was sore. This occurred once while he was in jail; but he never said there was foam in his mouth. In the two months before the homicide he was ill with influenza, suffered from insomnia, and during the two weeks previous he waked a number of times in the night "frightened and shaking." In April and May, while in jail, he had two brief attacks of diplopia for Io or 15 minutes; remembers another one some time before, while reading a newspaper in an office in Providence; he had headache, saw everything double, and had to stop what he was doing each time. This has happened to him twice, slightly, in Butler Hospital within two months after the trial, but not subsequently at the time of this writing; his general health has greatly improved since being there.

The data of the case, so far stated, include substantially all the evidence relating to the question of Palmer's condition on the night of the homicide: whether he was intoxicated and had an attack of alcoholic amnesia, or whether the evidence that he has 
been an epileptic from childhood, is entitled to consideration in explaining his act? Upon this latter point his further account of his experiences that night have an important bearing. The disorders of consciousness that he describes are themselves evidences of epilepsy to be studied and given their due weight.

Palmer's account of what occurred up to about 5 o'clock is substantiated, except as to the amount of whiskey he drank; his own statement and the absence of the effects that a larger quantity should have produced are to be accepted as sufficient evidence. He has no recollection of what happened from the time of going up to the billiard-room until after II o'clock, except the brief interval when he saw his wife lying on the floor. Upon close inquiry it appears that his memory did not stop abruptly; it is hazy as to his going up, and possibly being in the room. He says, "The next I remember I was bending over my wife. I saw her lying there and I have an indistinct recollection of putting a hassock under her head and seeing a bottle lying on the floor." "I thought something awful had happened and I said, 'My God, Addie! She's not dead!' or something like that; then everything left me as I stood up." He has always said he saw nothing else in the room; on being cross questioned when testifying, he said he thought her dress was something light-colored. He could not recall her face; he said this many times in the medical examinations-that he tried very hard to remember how she looked, but never could see her face, though he could remember other people's faces. He always described the vision as indistinct and dream-like. After that, he says, "The first impression was that I seemed to be walking up and down and then someone stood before me handing me some medicine. I thought it was a doctor." "He gave it to me several times." "Then two other men came in; I did not know them; they said something about its being a tough night. I got the impression that one was an officer. Then her little dog came in and he came with ears down, and he licked my hands and face and I said, 'My God, he knows something has happened.' He started to go where my wife was, and I said, 'My God, he is after her, don't let him go in there '; and I boohoo'd right out." "Then, it seems to me, that I went into the billiardroom, the two officers and myself. I took the cigars out of the box and left them for the men to smoke. I laid down in the billiard-room, but I could not keep still. Then we went down to the sitting-room; I lighted the gas-log and I kept walking up and down and they kept watching me; I went to the water-closet and one of the men followed me; I wondered why. I felt awful bad; they talked, but did not say much to me." Palmer's account further indicates the gradual clearing of his memory till he left the house in the morning. He said good-bye "when they helped me on with my coat. It was getting awful; I realized it more and more as if something awful had happened and as if someone else had done it, but that I was to blame for it; I could not get myself into it." 
He described circumstantially the drive to the court-room, and what was done and said there; after that he realized more what had happened, but, he says, "It did not seem as if it could be me; I did say, "My God, I would not have hurt a hair of her head.' I partly realized that I had done something and that I was somehow to blame for it."

The foregoing account reproduces very fully the details given by Palmer marking the beginning and end of the period of amnesia, and indicating that his memories, partial at first, gradually became more complete. The story told a month after the event naturally lacked some particulars that he would have remembered earlier; it was noted later that there was a further fading out of his memory of minor details, but it was consistent and there were no additions. It appeared conclusive from all the evidence that Palmer had been an epileptic from early childhood, but that in the later years of his life the disease had been manifested mainly by certain sensory and psychical equivalents, and there is much probability of some nocturnal attacks. There is, certainly, ample reason for considering epileptic as well as alcoholic amnesia in making a differential diagnosis of his condition at the time of the homicide.

The question of epilepsy presents problems that have become well defined in the study of this disease. With respect to the main question, as to whether it is consistent with the known facts to ascribe Palmer's sudden violence and homicide to an attack of epilepsy, it is hardly necessary to cite the numerous authorities whose observations and opinions establish the conclusion that epileptic seizures of that character frequently occur. Epileptics, though not having well-marked major attacks for years, may show the continuance of the disease by its manifestations in nocturnal attacks and in a great variety of forms of epileptic equivalents. In Palmer's case the "faint turns," "allgone feelings," "seeing double," etc., constitute symptoms regarded as characteristic of epilepsy in many recognized cases. It is not uncommon for the minor attacks to consist of, or to begin with, vertigo, or headache, or brief "absences," or disturbances so slight as to be unrecognized, and yet sometimes to be followed by very great disorders of consciousness. The condition may be such that the patient, with a certain degree of consciousness, performs actions habitual to him in an automatic 
manner; or he may ander away and so conduct himself as not to attract attention. Again, as is well known, the automatic actions are sudden outbreaks of rage or fear with impulsions to brutal homicidal acts. Suicidal impulses also occur in these conditions. Striking mental disturbances of variable duration sometimes occur just before the attack, with violent hallucinations and fright. The automatic condition after the seizure may be very brief and occupy but a few minutes; or it may continue for hours or days, and in some cases a much longer time. While in this state the patient may be excited, bewildered and confused, and appear as if intoxicated. The recovery may be gradual. It is admitted that unconsciousness is a fundamental characteristic of epilepsy, and, as a rule, that the epileptic does not retain a single recollection of the acts performed during the impulsive crisis; but it appears sometimes that the patient is fully conscious of the acts he commits and remembers them. The impulse to their commission is none the less irresistible, and is associated with acute mental suffering.' The memory may also be patchy, with obscure and dream-like recollections, more or less clear and prolonged, of single acts or occurrences while in the epileptic state."

In the study of the hypotheses of alcoholism and epilepsy in the Palmer case, the latter was strengthened as the inquiry progressed to its conclusion. But questions arose at the outset as to his condition during the four hours preceding the outbreak: Did the attack begin at 5 o'clock or at 9.20? How was the amnesia related to the epileptic seizure? Palmer was so unchanged in appearance and manner until 9 o'clock as to make an earlier onset improbable. The inquiry was thus directed to the literature of epileptic amnesia and alterations of consciousness.

There is a general absence of any mention of retrograde amnesia in epilepsy in articles or treatises on the disease in our language. Th. Ribot, in an article on memory; refers to the well-known phenomena of "mental automatism" in epilepsy, but

\footnotetext{
${ }^{2}$ Féré, Twentieth Century Practice, vol. X, p. 606.

References on the general subject: See Gowers, Epilepsy and Chronic Convulsive Diseases; Hirt, Diseases of the Nervous System; Clevenger, Med. Juris. of Insanity; and Féré, Épilepsies et Épileptiques.

‘Tuke's Dict. of Psychological Medicine.
} 
only mentions the retrograde form of amnesia as attendant upon accidents, cerebral shock, etc. In other articles in Tuke's Dictionary, the discussion of masked epilepsy, automatic acts, etc., includes no reference to retrograde amnesia.

Féré describes the amnesia of epilepsy as presenting several varieties. Most patients preserve some recollection of the prodromata, and the phenomena of the aura; and some recall having felt or seen the convulsive movements of their arms, or remember having heard their cry. But "others, on the contrary, present a retroactive amnesia which comprises recent occurrences. Several forms of amnesia may be observed in the same patient following different attacks; the retroactive amnesia has several times appeared to bear a certain relation to the severity of the attack."

Alzheimer, in an article on retrograde amnesia in epilepsy, refers to the numerous reports in the literature showing that after traumatism and hysterical attacks, a lapse of memory for a more or less protracted period preceding the traumatism or the attack may occur; this retrograde amnesia may be confined to individual acts, or a few hours, or it may comprise days and months; and, as it seems, it may sometimes take in the whole preceding life. He remarks that little attention has been paid to the retrograde amnesia occurring in conjunction with epileptic paroxysms (Féré and Sollier). Mentioning first the common forms of amnesia merely comprising the time of the attack, or the equivalent of an attack, he proceeds to discuss the rarer forms of retrograde amnesia occurring in peculiar mental conditions following epileptic paroxysms. The question is whether the attack, after which a period of amnesia extending further back than the attack itself is observed, was preceded by a disturbance of consciousness (pre-epileptic confusion) or not. In order to prove the absence of pre-epileptic confusion, it is necessary to show that the patient presented no evidence of disorder of consciousness before the attack. Describing the amnesias associated with the paroxysm, or an equivalent of one, he mentions among the differences in different cases those that are permanent or more or less complete, or those in which the recol-

${ }^{8}$ Féré, Épilepsies et Épileptiques, p. 94.

- Allg. Zeitsch. f. Psychiatrie, vol. LIII, p. 483. 
lection is absent immediately after the attack but may return later to a certain extent, or in which the recollection of events that have passed during the attack is present as the patient is coming out of it but becomes more and more faded. But the characteristics of the memories which belong to the time of the paroxysm are that they will be dream-like, indefinite and incomplete; while the memories which were lost by retrograde amnesia are, on their reappearance, sharp, clear and definite. Alzheimer reports three cases in which the amnesia of the retrograde type afterwards disappeared, but he notes the fact that the memories are sometimes permanently lost, referring to a case reported by Strumpell.'

Alzheimer's cases were (I) a patient who had after attacks two retrograde lapses of memory; one that extended over four weeks and cleared up after one week's duration; the other covered a year and a half before the attack, and memory began to return about three weeks after it; (2) a patient whose amnesia extended over a week previous to a series of attacks occurring in three days, and cleared up twenty-one days later; (3) a patient who had a series of attacks within six days followed by an amnesia that extended back two weeks before they began, and which cleared up three weeks after the attacks.

Strumpell's patient had a short series of attacks in one day; there was a loss of memory extending back three months before the seizures; and it was still continuing thirteen months later when the last information from the patient was heard.

Paul, reporting a case of retrograde amnesia following puerperal eclampsia, refers to its occurrence in epilepsy.

The diagnosis of alcoholism made on the night of the homicide had for its data substantially only the immediate facts then observed or learned from Palmer himself and the servants. There was no knowledge of his epileptic antecedents; it does not appear that epilepsy was then considered. It was quite natural that the severity of the mental disturbance, which resembled intoxication in some particulars, should suggest a considerable indulgence in alcohol; it was indeed necessary, considering his former tolerance of it, to assume that he drank much more than

'Deutsche Zeitsch. f. Nervenheilk., Bd. VIII, Heft 5 and 6.

- Archiv f. Psych., vol. XXXII, p. 25I. See abstract of case, Bost. Med. and Surg. Jour., Aug. 17, 1899, p. 165. 
he said he did if that must be considered the essential cause. In favor of alcoholism was the "smell of breath" and of the vomitus, and the interpretation then made of the mental symptoms; but if these are explained as bearing a close resemblance to epilepsy this fact is as much in favor of the latter as the former. Against alcoholism are the comparatively small amount of alcohol taken during the six hours before 9 o'clock and that the effects which had been produced by it at that time were too small to account for the sudden outbreak of violence within the next half hour. Neither is it adequate to explain an amnesia running back more than four hours before the attack and ending sharply enough to cause a notable change of manner and appearance. But it is more than probable that what Palmer is known to have drank, and his companions also, was enough to produce the symptom of " smell of breath" in any one. It should be granted also that "in cases predisposed to epilepsy even moderate doses of alcohol may produce the most severe psychical disturbances." But this does not conflict with the fact that Palmer may have drank to excess many times before without an epileptic seizure as a sequence. The hypothesis of acute alcoholism as explaining his condition during the night after the sudden and violent outbreak is not satisfactory and conclusive; it was the one first offered by "common sense" to both prosecution and defense in the case, but it did not then give any weight to the possible fact and effects of epilepsy. The facts justified an inquiry for a better explanation than alcoholism.

The diagnosis of epilepsy has for its foundation the fact that Palmer has been subject to that disease from his early childhood. The continuity of the history of epilepsy during his last eighteen years was not well brought out because of his poor memory for incidents of his life except striking events. He did not remember the one typical attack witnessed by the barber fourteen years ago, but the evidence given by himself would satisfy any medical inquiry that he had occasional "faint turns" during subsequent years when he felt as he did when he was "going to have an attack"; and they were of such a character as to be likely to escape ordinary recognition. Those who knew him most intimately are dead. In the nature of the case, he is more likely

\footnotetext{
- Kraepelin, Psychiatrie, 6th ed., 1899, vol. I, p. 49.
} 
than not to have had more recognizable attacks than he recollects previous to those he called " sunstroke," which there is reason to believe his attending physician regarded as epileptic. While the attacks have usually occurred far apart, the evidence indicates that in whatever form they may have happened, they have been tending to be more pronounced and frequent in the last two or three years; a tendency, however, naturally abated under conditions of a better regulated life.

The paroxysmal and violent character of the attack at the time of the homicide is most consistent with epilepsy; all that he is then alleged to have said and done, and what he himself says, are consistent with the epileptic state. The statements of the two physicians-who saw him in the process of recovering from the attack-that his memory appeared to have stopped in the billiard-room and to have begun to return after Dr. Hersey came; that sometimes he remembered and then did not remember; and that he had a brief, indistinct recollection of seeing his wife lying on the floor; refer to phenomena well known in epilepsy. It was of like character that during the automatic state of the attack he should know with varying clearness, and then seem not to know, what had happened; the same is true of the action of his memory from the time of its beginning to return when the doctor gave him medicine and when he began to change from being excited and confused to being "rational" with no appearance of "frenzy," but with a varying cloudiness of memory and understanding of what he was told he had done. As the physicians who examined him have seen the later fading of his memories, there were two lasting impressions made upon his mind that he does not lose: the "coming to himself" and seeing the doctor standing before him; and, afterwards, the incident of his wife's little dog coming to him with actions unusual for it; he never speaks of this without emotion. Comparatively the sense of reality of seeing her lie dead on the floor is so much less, that in speaking of this he is less affected.

In regard to the onset of the paroxysm, how it began will never be known, and can only be conjectured. His fright and belief that his wife had tried to kill him first are not difficult to credit as being a part of an hallucinatory delusion that might have ushered in the attack; his amiable condition so shortly before, 
the peacefulness of the customary progress of affairs in the room, and the certainty that he made ready the bottle of porter and that his wife drank it, which must have occupied the time till close upon the shooting, demand the sudden intrusion of some terrifying belief that could so greatly and suddenly change the man. ${ }^{20}$ The other epileptic characteristics of the attack being granted, there is nothing incredible in the first manifestations as belonging to its onset. But next to the suddenness and violence of the outbreak, in the absence of other satisfactory cause for it, the most conclusive feature of the whole attack was the behavior of the amnesia, and the patch of dream-like recollection in the midst of the act. The retrograde amnesia is further proven by the absence of all evidence of disturbance of consciousness that can be construed to be a pre-epileptic confusion.

Other conjectures also offer themselves as to how the trouble began; they need to be mentioned to avoid the appearance of their not having been considered. Supposing that "some kind of a quarrel arose between Palmer and his wife," it is incredible that he voluntarily and in his right mind took the pistol from its place to shoot her. It was near to this place that her body lay. But, supposing, again, that instead of his being seized with an epileptic hallucination, and taking the pistol to protect himself against imaginary danger, causing her, after drinking the porter, to leave her customary place and go to disarm him; and then assuming that he, remembering all the circumstances, could say that she becoming violently angry ran to get the pistol, threatening to shoot him; it would not be incredible in the light of previous occurrences. Assuming this, it must be assumed, further, that he seized the pistol from her hand and shot her in his fear and excitement, believing she tried to kill him first. The question would then arise, if his fear and the realization that he had killed her (a realization of which he had been entirely capable twenty minutes before) would have been a sufficient shock to produce a mental state of automatism and cause an amnesia retrograding four hours and continuing two hours thereafter? Then, does this explanation account for the epileptic characteristics of the

\footnotetext{
${ }^{10}$ It has been said that he once shot at her. In the medical examinations, Palmer was asked to relate instances of quarrels with his wife. He frankly told of occasions of his own high words to her, and hers to him. He never offered violence to her; on two or three occasions she had threatened him with the pistol,-once about five years ago she did so; he took the pistol from her hand and pointing it downward and backward, emptied it, the shots being fired so that they went into the foot-board of a bed. The incident evidently closed with little alarm on either side.
} 
period of automatisn, the patchy memory, the manner of its recovery? Or, on the other hand, accepting the epileptic state as manifest, was the attack of epilepsy itself brought on by the mental shock of the scene? In answer, it seems conservative and reasonable to point to the direct and observed manifestations so strikingly epileptic in character, and to accept these as determining the fact. Thus, as this happened in an epileptic person, there is afforded the best explanation not only of the observed phenomena, but of the peculiar amnesia. The preponderance of the evidences of an epileptic attack is so well established that it does not seem necessary to prove at what moment it began in the course of the incidents attending its onset, however reasonable present conjectures may be as to what they were. In the last resort, there was in this case an "attack" with retrograde amnesia in a person who has been subject to epilepsy all his life; these facts are indisputable.

The weight of evidence was believed by the physicians called by the defense to be conclusive that Palmer was irresponsible for the crime with which he was charged; and that when he killed his wife, he was in an epileptic attack."

${ }^{11}$ Through the courtesy of Dr. Blumer, the writer visited Mr. Palmer at the Butler Hospital thirteen months after the homicide; this permits this latest information of the case to be noted here. Palmer was greatly improved in health, had gained in weight, and with his daily exercise in long walks, driving and wheeling, he looked hardy and well; he said he was better for the change from his bad ways of life for years before he was brought to the hospital. He was asked if he could not remember something more of what happened last year. He said that he could not, though he had tried very hard to do so;-" and about that night,

(a guest of the evening) said a little while ago it was very strange that I could do such a thing when I was all right such a little while before." “I can't make it out at all. If I only knew how it begun I could tell something about it." "Could I have had more whiskey than I know about? I've wondered what I did after they (the guests) went away, and if I took more when I went down cellar that last time." When told that his wife went with him, he evidently had no memory of it, and said: "Well, it must have been that Mt. Vernon whiskey; _- said, when I bought it of him, that it was Ioo per cent." $\mathrm{He}$ adhered literally to his former statements of the amount he drank during that day. When asked if he had had any nervous feelings since he came to the hospital, he replied: "No, nothing at all, except seeing double those two times last summer that I told you about; they were very slight and didn't last long; I am feeling better than for a good many years before I came here."

Palmer still has the "theory of alcoholism," with the same weak appreciation, that was apparent last year, of the whole affair, and of the significance of the attacks and their purport as explaining some of his 
The counsel for Palmer based their defense upon the foregoing conclusions. It was the conviction of the absolute truth of his statements that led to his being placed first upon the witnessstand in his own defense as has been stated, and absolutely without instructions. It was a part of the quality of his mind that he had small invention, and little could be got out of his mind but concrete memories; he went very little into the reasons for things, and told the same unvarnished story to any one who might ask. It was this unique feature that gave the case its sure foundation; those who studied him most carefully were forced to this conviction, and there could have been but few of the people in the court-room who did not soon accept it after he began his story.

After the testimony for the defense had been partly introduced, a conference of the experts was arranged, as had been desired from the beginning of the trial by those on both sides. An afternoon was devoted to an examination of Palmer by the experts for the State, and to the consideration of the testimony, some of which had not yet been introduced in court, including matters that had come to the knowledge of the experts for the defense that had the value of medical evidence.

The result of this conference was a ready agreement to the irresponsibility of Palmer, and that he was insane. The experts

experiences. At the same time his appreciation of kindnesses shown him, his amiability and desire to please others, his patience under circumstances of which he feels the painfulness, and the correctness of his conduct, sustain the estimate of his character stated in the beginning of this paper. It is interesting to consider that Palmer not being vicious by nature, it is not alone that he fell in with baneful associations, but that his natural unfitness to cope with them was increased by the tender protection given in his youth by his mother because of his disease. It is evident that there was a decided tendency to the abatement of it, as he came to adult life, and if he could have been under stronger wholesome influences and guidance, he might not only have lived respectably, but with more freedom from the effects of his malady. Now the radical change of the last nine months in his habits and manner of living, and his amenability to control, already indicate that he may enjoy a greater immunity from his disease than might have been expected; the absence or rarity of epileptic manifestations in any form, under favoring conditions, would not be unlike this disease and furnish no proof against its more active existence heretofore. 
for the State were not ready to adopt the conclusion, but did not deny it, that the homicide was committed during an attack of epilepsy; the time was too brief for a review of the data of evidence, and of the authorities in support of that diagnosis and explanation of the occurrence of the act. This study of the case and the inquiry here presented will permit such a review.

The following report was addressed to the Attorney-General, prepared by the experts for the defense with certain modifications suggested by those for the State, and was agreed to and signed by all the members of the conference. ${ }^{12}$

"We, the undersigned, having examined Amos D. Palmer as to his mental condition, with reference to the indictment against him for the killing of his wife on the night of February 12, 1899, hereby report that we jointly agree in the opinion that he is the subject of mental disease, and that the act was committed under the influence of that disease; and, in our opinion, he is therefore not responsible for his homicidal act, and proper measures should be taken to protect him and the public from further consequences of his mental disease."

The following report was also made to the Attorney-General by the experts for the State:

"The undersigned physicians, appointed by you as Attorney-General of Rhode Island, to assist and counsel the State in the trial of Amos D. Palmer, at present under indictment for the murder of his wife, have this day examined the said prisoner at length; have consulted with the medical counsellors for the defense; have reviewed the evidence submitted and the facts obtained in relation to said prisoner yet to be presented in evidence, and as a result thereof beg to submit the following opinion:

We believe that the said Amos D. Palmer, on the night of Feb. I2, 1899, at the time said Palmer shot his wife, was irresponsible by virtue of mental incompetency and a state of unconsciousness and impaired will.

We recommend that said Palmer should be acquitted for the reasons herein stated, but as his mental incapacity is incurable. appropriate measures should be taken to protect the public and himself from further consequences of his disease."

These conclusions, being acceptable to the counsel on both sides, were presented to the court as the ground for the disposi-

12 For the defense: George F. Jelly, Edward Cowles, Walter Channing, W. H. Palmer, and F. H. Peckham, Jr. For the State: P. M. Wise, C. P. Bancroit, G. F. Keene. The trial was held in the Supreme Court before Justice Wilbur. Counsel for the State. Willard B. Tanner, Attorney-General; for the defense, Charles A. Wilson and Rathbone Gardner. 
tion of the case; the court not having power to direct a verdict, it required a clear acquittal by the jury. Then each of the experts testified, giving briefly his opinion. In his charge, the Court said: "If you believe this testimony, there is only one conclusion, and that should be that Amos D. Palmer is not guilty by reason of insanity. If you agree upon it, let that be your verdict." The jury immediately rendered that verdict, and subsequently Palmer was consigned by Governor Dyer to the custody of the Butler Hospital, at Providence.

In regard to expert testimony, and the repute in which it has come to be held in too many instances, it is with great satisfaction that the present record is made of the consideration with which the medical evidence was treated by the court, and counsel on both sides. The case rested essentially upon the medicolegal questions, and it was most gratifying to the medical expert witnesses that they were permitted, as they all desired, to meet in a judicial conference and to reach a joint conclusion, which in their belief serves both the ends of justice and humanity. The medical counsellors found, it is true, that there were legitimate differences of professional opinion upon points of minor importance beside the main question-differences that could have been exploited by antagonistic advocates to the confusion of the real issue; but it was found also that, although naturally opponents from the attorney's point of view, it was possible on their own professional ground, to sit in medical judgment with mutual respect and confidence; and to render a joint opinion upon a: matter that belongs to their professional province with something of the sense of self-respect and propriety that must pertain to the judgments of the judicial bench. This claims consideration as a method of procedure that ought to prevail. 